Deuterium retention in tungsten and tungsten-tantalum alloys exposed to high-flux deuterium plasmas

This article has been downloaded from IOPscience. Please scroll down to see the full text article.

2012 Nucl. Fusion 52103021

(http://iopscience.iop.org/0029-5515/52/10/103021)

View the table of contents for this issue, or go to the journal homepage for more

Download details:

IP Address: 193.190.187.220

The article was downloaded on 02/10/2012 at 10:46

Please note that terms and conditions apply. 


\title{
Deuterium retention in tungsten and tungsten-tantalum alloys exposed to high-flux deuterium plasmas
}

\author{
Y. Zayachuk ${ }^{1,2, a}$, M.H.J. 't Hoen ${ }^{3}$, P.A. Zeijlmans \\ van Emmichoven ${ }^{3}$, I. Uytdenhouwen ${ }^{1}$ and G. van Oost $^{2}$ \\ ${ }^{1}$ SCK·CEN, Boeretang 200, $2400 \mathrm{Mol}$, Belgium \\ ${ }^{2}$ Department of Applied Physics, Ghent University, Plateaustraat 22, 9000 Ghent, Belgium \\ ${ }^{3}$ FOM Institute DIFFER - Dutch Institute for Fundamental Energy Research, Edisonbaan \\ 14, 3439 MN Nieuwegein, The Netherlands \\ E-mail: yzayachu@sckcen.be
}

Received 13 April 2012, accepted for publication 29 August 2012

Published 24 September 2012

Online at stacks.iop.org/NF/52/103021

\begin{abstract}
A direct comparison of deuterium retention in samples of tungsten and two grades of tungsten-tantalum alloys-W$1 \% \mathrm{Ta}$ and $\mathrm{W}-5 \% \mathrm{Ta}$, exposed to deuterium plasmas (ion flux $\sim 10^{24} \mathrm{~m}^{-2} \mathrm{~s}^{-1}$, ion energy at the biased target $\sim 50 \mathrm{eV}$ ) at the plasma generator Pilot-PSI was performed using thermal desorption spectroscopy (TDS). No systematic difference in terms of total retention in tungsten and tungsten-tantalum was identified. The measured retention value for each grade did not deviate by more than $24 \%$ from the value averaged over the three grades exposed to the same conditions. No additional desorption peaks appeared in the TDS spectra of the W-Ta samples as compared with the $\mathrm{W}$ target, indicating that no additional kinds of traps are introduced by the alloying of $\mathrm{W}$ with Ta. In the course of the experiment the same samples were exposed to the same plasma conditions several times, and it is demonstrated that samples with the history of prior exposures yield an increase in deuterium retention of up to $130 \%$ under the investigated conditions compared with the samples that were not exposed before. We consider this as evidence that exposure of the considered materials to ions with energy below the displacement threshold generates additional traps for deuterium. The positions of the release peaks caused by these traps are similar for $\mathrm{W}$ and $\mathrm{W}-\mathrm{Ta}$, which indicates that the corresponding traps are of the same kind.
\end{abstract}

(Some figures may appear in colour only in the online journal)

\section{Introduction}

Currently, tungsten and carbon fibre composites are considered as candidate materials for the ITER divertor [1]. The practical use of tungsten is hindered by its high ductile-to-brittle transition temperature (DBTT). Therefore, tungsten alloys with better machinability are considered to be used instead [2]. However, the retention of hydrogen isotopes (including radioactive tritium) in binary tungsten alloys has not been extensively studied to date [3,4].

In this work, we examined the deuterium retention in W-Ta alloys using thermal desorption spectroscopy (TDS). The main goal of our experiments was to perform a direct comparison of deuterium retention in tungsten and in tungstentantalum alloys exposed to a high-flux deuterium plasma (keeping the exposure conditions the same for different grades). We also aimed at clarifying whether or not the presence of tantalum introduced new types of traps. It was

a Author to whom any correspondence should be addressed. therefore investigated whether additional desorption peaks appear in the TDS spectra of W-Ta samples as compared with those of W. In addition, we aimed at clarifying the effect of subsequent plasma exposures on deuterium retention, the so-called history effect, and its dependence on the alloying of W with Ta.

In our study we used polycrystalline samples. The samples were exposed to high-flux deuterium plasmas $\left(\sim 10^{24}\right.$ ions $\left.\mathrm{m}^{-2} \mathrm{~s}^{-1}\right)$ in the linear plasma simulator Pilot-PSI.

\section{Experiment}

The experimental part of the work was performed at the linear plasma generator Pilot-PSI at the FOM Institute DIFFER [5]. The plasma source in Pilot-PSI is based on a cascaded arc discharge, which generates high electron density $\left(\leqslant 10^{20} \mathrm{~m}^{-3}\right)$, low electron temperature $(\leqslant 5 \mathrm{eV})$ plasmas and operates in the pulsed regime. The high density is provided by focusing of the plasma beam by electromagnetic coils surrounding the 
Table 1. Exposure conditions: maximum exposure flux and maximum exposure temperature.

\begin{tabular}{lllll}
\hline Samples & Exposure/TDS after & W & W-1\% Ta & W-5\% Ta \\
\hline With history & First/1 h 50 min & $8.9 \times 10^{23} \mathrm{~m}^{-2} \mathrm{~s}^{-1}$ & $8.5 \times 10^{23} \mathrm{~m}^{-2} \mathrm{~s}^{-1}$ & $8.2 \times 10^{23} \mathrm{~m}^{-2} \mathrm{~s}^{-1}$ \\
& & $478 \mathrm{~K}$ & $470 \mathrm{~K}$ & $478 \mathrm{~K}$ \\
& Second/1 h 50 min & $8.6 \times 10^{23} \mathrm{~m}^{-2} \mathrm{~s}^{-1}$ & $1.0 \times 10^{24} \mathrm{~m}^{-2} \mathrm{~s}^{-1}$ & $9.1 \times 10^{23} \mathrm{~m}^{-2} \mathrm{~s}^{-1}$ \\
& & $463 \mathrm{~K}$ & $498 \mathrm{~K}$ & $488 \mathrm{~K}$ \\
& Third/a week & $8.5 \times 10^{23} \mathrm{~m}^{-2} \mathrm{~s}^{-1}$ & $9.0 \times 10^{23} \mathrm{~m}^{-2} \mathrm{~s}^{-1}$ & $8.7 \times 10^{23} \mathrm{~m}^{-2} \mathrm{~s}^{-1}$ \\
& & $463 \mathrm{~K}$ & $498 \mathrm{~K}$ & $498 \mathrm{~K}$ \\
Without history & First/a week & $7.8 \times 10^{23} \mathrm{~m}^{-2} \mathrm{~s}^{-1}$ & $9.9 \times 10^{23} \mathrm{~m}^{-2} \mathrm{~s}^{-1}$ & $4.8 \times 10^{23} \mathrm{~m}^{-2} \mathrm{~s}^{-1}$ \\
& & $508 \mathrm{~K}$ & $483 \mathrm{~K}$ & $396 \mathrm{~K}$ \\
\hline
\end{tabular}

plasma chamber. The plasma beam is not uniform-electron temperature and density profiles (and therefore also particle and heat flux profiles) are roughly Gaussian with FWHM being $\sim 1 \mathrm{~cm}$. To characterize the beam profile, the maximum density and surface temperature, corresponding to the centre of the beam, are indicated it the text.

The electron temperature and density are measured by Thomson scattering. The ion flux is then calculated (under the assumption that the ion temperature is equal to the electron temperature) as [5]

$$
\Phi=\frac{n_{\mathrm{e}}}{2} \sqrt{\frac{2 k_{\mathrm{B}} T}{m_{\mathrm{D}}}},
$$

with $m_{\mathrm{D}}$ the mass of the deuterium ion, $k_{\mathrm{B}}$ the Boltzmann constant, $T$ the electron temperature and $n_{\mathrm{e}}$ the electron density.

The surface temperature of a specimen is monitored by an IR camera.

In order to avoid creation of defects by displacement damage, the energy of the ions was kept well below the displacement damage threshold for $\mathrm{D}^{+}$ions in tungsten ( $\sim 940 \mathrm{eV}[6])$, namely close to $50 \mathrm{eV}$.

Two grades of powder metallurgy W-Ta alloy were examined-one containing 1 mass $\%$ of Ta and the other 5 mass $\%$ of Ta. The actual Ta content in both grades was measured by energy-dispersive $\mathrm{x}$-ray spectroscopy (EDX) and was found to be equal to the specified values of $1 \%$ and $5 \%$. It was also found that Ta and $\mathrm{W}$ are uniformly mixed, no Ta precipitates were observed. In addition, we also examined samples of powder metallurgy W. All investigated samples were polycrystalline and were provided by Plansee. The samples were discs of $20 \mathrm{~mm}$ diameter and had a thickness of $1 \mathrm{~mm}$. All samples were mechanically polished. Unless otherwise stated, they were subsequently annealed in vacuum at $1300 \mathrm{~K}$ for $1 \mathrm{~h}$.

Retention measurements were performed with TDS. The maximum temperature was $1273 \mathrm{~K}$, the temperature ramp was $0.5 \mathrm{~K} \mathrm{~s}^{-1}$ and the holding time at the maximum temperature was $5 \mathrm{~min}$. The release flux of molecular $\mathrm{HD}$ and $\mathrm{D}_{2}$ was measured by a quadrupole mass spectrometer.

Quantification of the mass 4 signal, corresponding to the release of $D_{2}$, was performed using a calibrated $D_{2}$ leak. Quantification of the mass 3 signal (HD) was performed using the averaged value of the signals of two calibrated leaks $-\mathrm{H}_{2}$ and $\mathrm{D}_{2}$.

Signals of other deuterium-containing molecular compounds, such as $\mathrm{D}_{2} \mathrm{O}$ and $\mathrm{HDO}$, were also detected, but because of the absence of the corresponding calibrated leaks, those could not be quantified. However, we believe that their contribution to the total retention is negligible. The reason is the following: we have the measurements of signals of masses 3,4 , 19 and 20 for the sample that was not exposed to the plasmathat is, the measurement of background. It can be seen that the signal of mass 3 (as well as mass 4), measured for the deuterium-exposed sample is orders of magnitude higher than the corresponding values of background. On the other hand, the corresponding signals of masses 19 and 20 fluctuate around the background value. Therefore, we conclude that the release of $\mathrm{HDO}$ and $\mathrm{D}_{2} \mathrm{O}$ does not contribute any significant fraction to the total deuterium release and can be neglected, so that measurements of the release of $\mathrm{HD}$ and $\mathrm{D}_{2}$ only adequately characterize the total deuterium retention, and therefore the analysis of retention was performed based on the contributions of $\mathrm{HD}$ and $\mathrm{D}_{2}$.

The experimental sequence was the following. Two samples of each grade (i.e. W, W-1\% Ta, W-5\% Ta) were used. One of the samples of each grade was exposed in Pilot-PSI once, with TDS measurements performed a week after the exposure. In the following, we will refer to this set of samples as the 'samples without history'. The other sample was exposed once, with TDS performed as fast as was technically possible ( $1 \mathrm{~h} 50 \mathrm{~min} \pm 4 \mathrm{~min}$ ) after the exposure. In the following, these measurements will be referred to as 'fast TDS'. After that, the same sample was exposed again, and again TDS was performed $1 \mathrm{~h} 50 \mathrm{~min}$ after the exposure. After that, the same sample was exposed again, but now TDS was performed a week after exposure. The samples from this set are referred to as 'the samples with history'. The week lag time between exposure and TDS measurements ensured that only trapped inventories, properly characterizing the trapping properties of the investigated materials, were measured.

All the exposures were performed at as identical exposure conditions as technically achievable. The maximum flux in the centre of the beam on all targets was in the range $8 \times 10^{23}$ $1 \times 10^{24} \mathrm{~m}^{-2} \mathrm{~s}^{-1}$, the maximum surface temperature in the range $460-510 \mathrm{~K}$, with the exception of the $\mathrm{W}-5 \%$ Ta sample without history, for which the flux was $5 \times 10^{23} \mathrm{~m}^{-2} \mathrm{~s}^{-1}$ and the maximum temperature $400 \mathrm{~K}$. The exposure time in all cases was $70 \mathrm{~s}$, and all exposures were performed in a single pulse. Exposure conditions for each exposure of each sample are summarized in table 1 . The temperature during exposure ensured that vacancies were not mobile (in W, vacancies become mobile at 550-600 K $[7,8])$.

In all cases, the samples were stored in air between the end of exposure and the beginning of the TDS measurement. 

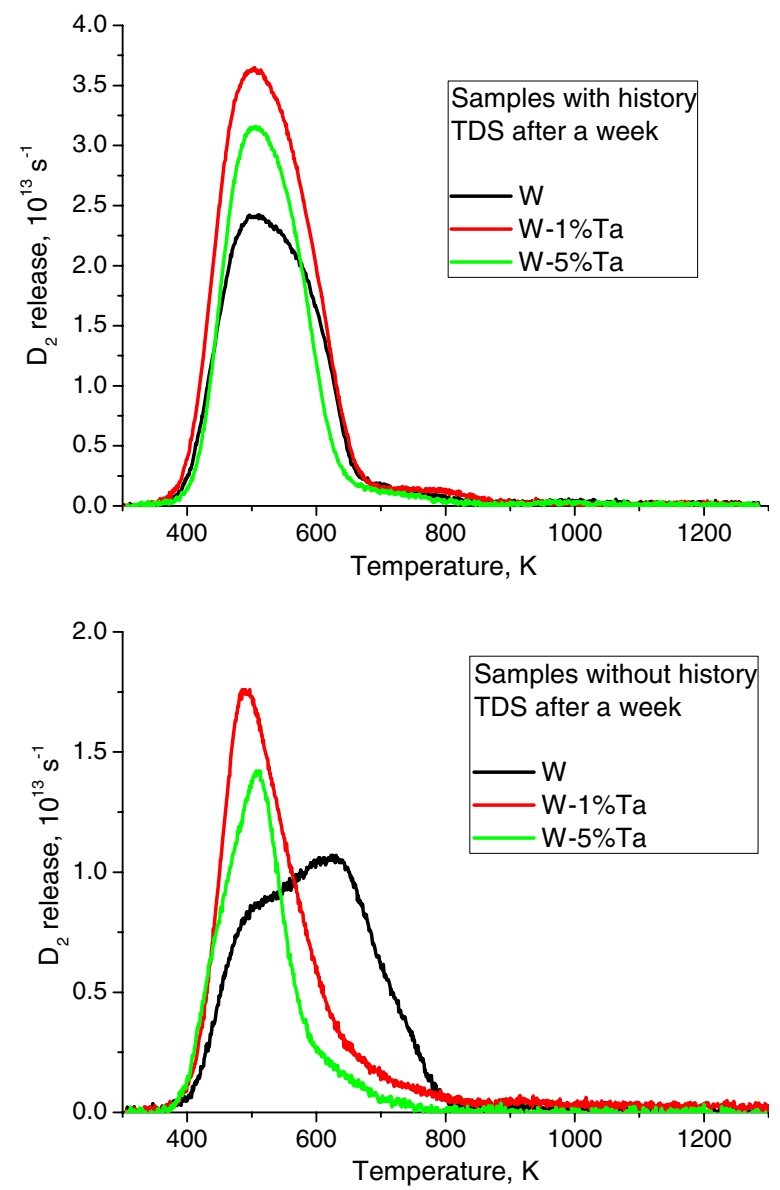

Figure 1. TDS spectra of $\mathrm{D}_{2}$ release from the samples of $\mathrm{W}$, $\mathrm{W}-1 \% \mathrm{Ta}$ and $\mathrm{W}-5 \% \mathrm{Ta}$ with history and without history of previous exposures.

\section{Experimental results}

\subsection{TDS of the samples of tungsten and tungsten-tantalum alloys}

Figure 1 presents the TDS spectra of the investigated samples of $\mathrm{W}, \mathrm{W}-1 \% \mathrm{Ta}$ and $\mathrm{W}-5 \% \mathrm{Ta}$. It is evident that (i) the TDS spectra of the W-Ta samples do not have any additional desorption peaks as compared with the samples of W; (ii) TDS spectra of all the investigated samples contain the lowtemperature release peak which has the same temperature position at $\sim 500 \mathrm{~K}$; (iii) the spectra of the $\mathrm{W}$ samples appear to consist of two unresolved peaks with a high-temperature peak at $600-650 \mathrm{~K}$ while the spectra of the W-Ta samples have only a long desorption tail stretching into the hightemperature region without any noticeable high-temperature peak.

The fraction of deuterium released as HD varied from run to run and contributed from $16 \%$ to $28 \%$ of the deuterium retention.

\subsection{The first exposure: fast TDS and TDS after a week}

Figure 2 presents the comparison of the desorption spectra obtained for the exposures of the samples without history and
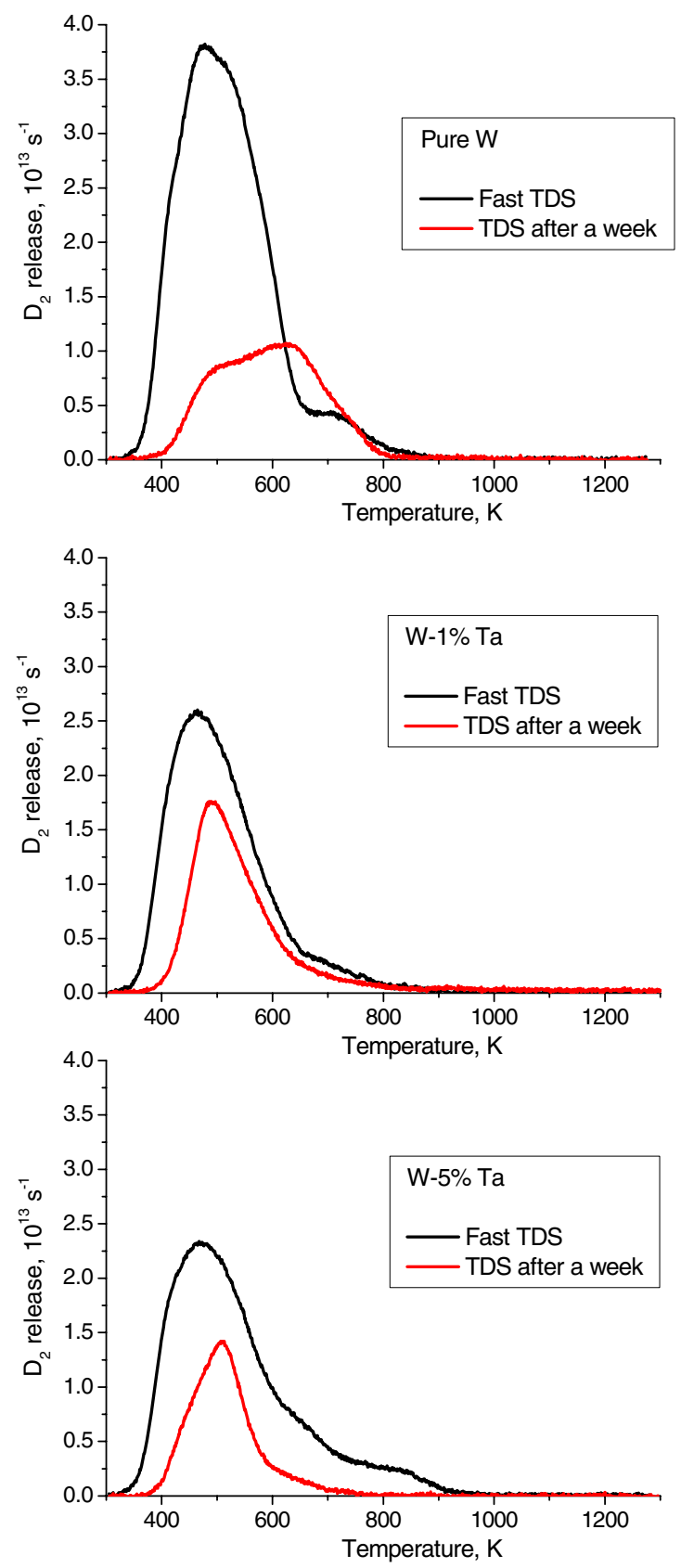

Figure 2. Comparison of desorption spectra, recorded shortly after the first exposure of the sample with history ('fast TDS') and a week after the exposure (for the samples without history).

for the first exposure of samples with history. This is, in essence, the comparison between desorption spectra of the equivalent samples (since samples with history have not yet been exposed before), measured about $1 \mathrm{~h} 50 \mathrm{~min}$ and a week, respectively, after the plasma exposure. The presented data demonstrate several important details: (i) deuterium release in the TDS spectra measured $1 \mathrm{~h} 50 \mathrm{~min}$ after the exposure starts at considerably lower, and stops at somewhat higher, temperatures compared with those measured a week after the exposure; (ii) the total amount retained in the samples shortly after the exposure is considerably higher than a week after. 

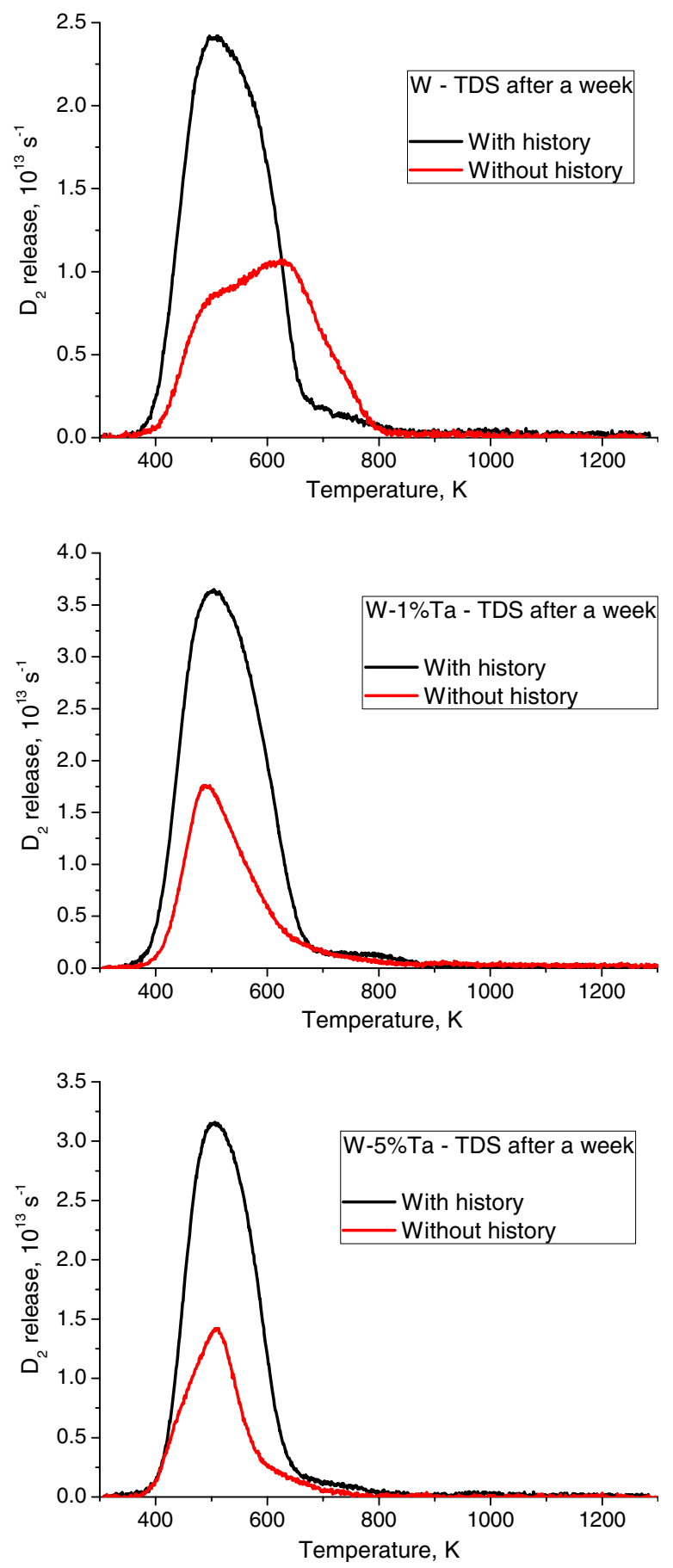

Figure 3. Comparison of the spectra of $\mathrm{D}_{2}$ release, recorded a week after the exposure, for the samples with and without history.

\subsection{Samples with and without history: TDS after a week}

Figure 3 presents the comparison of the spectra measured after a week lag between the exposure and TDS, for samples with and without history. It demonstrates that in all investigated grades history of prior exposures influences the amount of retained deuterium. For all grades the total amount of deuterium remaining after a week in the sample with previous history of exposures is higher than for the sample that was exposed only once. In general, the shape of the spectrum

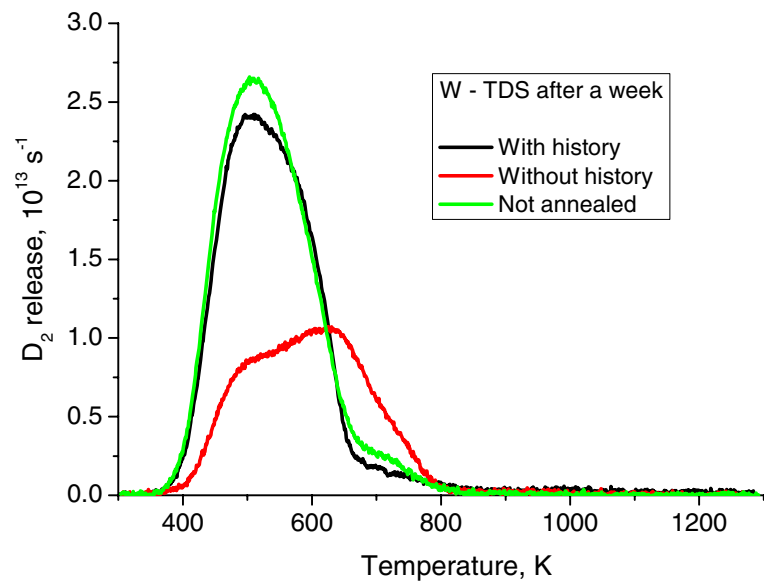

Figure 4. TDS spectra of $\mathrm{D}_{2}$ release from the annealed $\mathrm{W}$ sample with history, annealed and not annealed $\mathrm{W}$ samples without history, measured a week after the plasma exposure.

is different for samples with and without history, while the position of the release peaks remains virtually unchanged.

\subsection{Annealed and unannealed samples}

An additional sample of $\mathrm{W}$ was exposed (only once) to similar plasma conditions as all the other samples (maximum flux $8 \times 10^{23} \mathrm{~m}^{-2} \mathrm{~s}^{-1}$, maximum temperature $463 \mathrm{~K}$ ), but this one was polished and not annealed before the exposure. TDS on this sample was performed a week after the exposure. Figure 4 presents the comparison of the desorption spectrum of this sample with the spectra of the annealed samples with and without history, measured a week after exposure.

It is evident that the spectra of the annealed sample with history and the unannealed sample without history are very similar. Also, the total retention for these samples is higher as compared with the annealed sample without history.

\section{Discussion}

A general overview of the total amounts of deuterium retained after each performed exposure is presented in table 2. The total retained deuterium amount was calculated by integration of total deuterium release flux $\Gamma_{\mathrm{D}}$, calculated as

$$
\Gamma_{\mathrm{D}}=\Gamma_{\mathrm{HD}}+2 \Gamma_{\mathrm{D}_{2}},
$$

where $\Gamma_{\mathrm{HD}}$ is the release flux of molecular HD, and $\Gamma_{\mathrm{D}_{2}}$ is the release flux of molecular $\mathrm{D}_{2}$.

From table 2 it can be seen that generally in terms of total retention there is no systematic difference between $\mathrm{W}$ and $\mathrm{W}-$ $\mathrm{Ta}$, nor between the two grades of $\mathrm{W}-\mathrm{Ta}$, i.e. $\mathrm{W}-1 \% \mathrm{Ta}$ and $\mathrm{W}-5 \% \mathrm{Ta}$. The measured values of total retention for each grade did not deviate from the average value for each exposure step by more than $24 \%$. This suggests that the implementation of $\mathrm{W}-\mathrm{Ta}$ as a plasma-facing material will not lead to a significant increase in tritium retention in the corresponding plasma-facing components. It should, however, be noted that this is based on experiments in a limited temperature range and that for a decisive answer it would be necessary to perform comparable measurements in a wider range of surface temperatures and ion fluxes. 
Table 2. Total deuterium amount retained in the investigated samples for different conditions and its deviation from the value averaged over the three grades under the same conditions.

\begin{tabular}{|c|c|c|c|c|}
\hline Samples & Exposure/TDS after & W & $\mathrm{W}-1 \% \mathrm{Ta}$ & $\mathrm{W}-5 \% \mathrm{Ta}$ \\
\hline \multirow{6}{*}{ With history } & \multirow{2}{*}{ First/1 h $50 \mathrm{~min}$} & $3.9 \times 10^{16}$ & $2.5 \times 10^{16}$ & $3.0 \times 10^{16}$ \\
\hline & & $+24 \%$ & $-20 \%$ & $-4 \%$ \\
\hline & \multirow{2}{*}{ Second/1 h $50 \mathrm{~min}$} & $3.5 \times 10^{16}$ & $3.9 \times 10^{16}$ & $3.8 \times 10^{16}$ \\
\hline & & $-6 \%$ & $+4 \%$ & $+2 \%$ \\
\hline & \multirow{2}{*}{ Third/a week } & $2.3 \times 10^{16}$ & $3.1 \times 10^{16}$ & $2.3 \times 10^{16}$ \\
\hline & & $-10 \%$ & $+20 \%$ & $-10 \%$ \\
\hline \multirow{2}{*}{ Without history } & \multirow{2}{*}{ First/A week } & $1.4 \times 10^{16}$ & $1.4 \times 10^{16}$ & $1.0 \times 10^{16}$ \\
\hline & & $+10.5 \%$ & $+10.5 \%$ & $-21 \%$ \\
\hline
\end{tabular}

The fact that the total amount of retained deuterium is considerably lower for the samples that were stored for a week after the exposure prior to TDS measurement, compared with the samples that were measured shortly after the exposure, combined with the fact that the release as measured in fast TDS starts at considerably lower temperatures than that measured in TDS after a week, indicates that $1 \mathrm{~h} 50 \mathrm{~min}$ after the exposure there is still a large amount of deuterium atoms in the weakly bound state. Careful consideration of the fast TDS spectra of the W sample suggests that it features a small unresolved peak at $\sim 420 \mathrm{~K}$. Therefore, we suggest that the difference in the measured retention between fast TDS and TDS after a week is caused by traps with a small trapping energy, which still retain some deuterium $1 \mathrm{~h} 50 \mathrm{~min}$ after the exposure, possibly together with a small contribution of solute deuterium, but which is largely released during the waiting time of one week at room temperature. It is known that in tungsten dislocations exhibit the lowest trapping energy among all the defects, so this low-temperature peak can be attributed to the trapping on dislocations. Since these atoms are weakly bound to the crystal lattice of the material, they are quickly released even at room temperature. Therefore, TDS performed a week after the exposure reveals only strongly trapped deuterium. Similar observations of the decrease in the retained deuterium amount in tungsten over the waiting (storage) time were reported in $[6,9,10]$.

As was already mentioned, for all grades the total amount of deuterium remaining after a week in the sample with the history of prior exposures is higher than for the sample that was exposed only once. Figures $1(a), 2(b)$ and table 2 indicate that this holds true for the total amount of deuterium remaining after $1 \mathrm{~h} 50 \mathrm{~min}$ in the samples of both $\mathrm{W}-\mathrm{Ta}$ grades. At the same time, for $\mathrm{W}$ the second exposure shows a reduction in $\mathrm{D}$ retention compared with the first exposure. Taking into account the previous statement and comparing the results of fast TDS and those measured a week later, this indicates that the impact of the pre-exposure on the dynamics of solute deuterium release is different for $\mathrm{W}$ and $\mathrm{W}-\mathrm{Ta}$.

For all grades the trapped deuterium amount as measured by TDS after a week is higher for the samples that were exposed before than for the samples that were not. This indicates that plasma exposure creates additional trapping sites within the material of the sample. The possibility of modification of plasma-exposed tungsten leading to creation of additional damage has been demonstrated in earlier works ([11, 12]).

Enhanced retention in pre-exposed samples has been observed before $[13,14]$. However, there exists a significant difference between the presented data and the ones available from the literature. The impact of the pre-exposure of the samples on the retention in subsequent exposures was reported to arise due to the high-energy $(\sim 1 \mathrm{keV}$, while in our experiments it was only $\sim 50 \mathrm{eV}$ ), low-flux ion exposure and manifested itself as an increase in a high-temperature desorption peak. In our experiments, however, pre-exposure leads to an increase in the low-temperature desorption peak. For the W-Ta samples we did not observe any profound hightemperature peak at all.

As was mentioned in section 3.1, the samples of W-Ta do not have additional desorption peaks as compared with $\mathrm{W}$. This means that the alloying of tungsten with tantalum does not introduce additional kinds of traps. The fact that deuterium retention is not systematically higher for W-Ta indicates that this alloying does not increase the concentration of trapping sites either. On the other hand, the position of one of the release peaks of $\mathrm{W}$ and of the only release peak of W-Ta is similar for all investigated grades. Since the TDS conditions were identical, this means that the corresponding trapping energy is the same. Therefore, it seems likely that there exists a common kind of trapping site for $\mathrm{W}$ and for $\mathrm{W}-\mathrm{Ta}$, while $\mathrm{W}$ possesses additional kinds of traps, absent (or present in considerably lower concentrations) in W-Ta.

It should be noted that the surface temperature profile, as mentioned in section 2, is non-uniform during the exposure. Therefore, the shape of the measured TDS spectrum might be affected by the fact that it contains contributions from different positions on the sample, which were in fact exposed at different temperatures. However, this effect, if present, is compensated for by the fact that we perform the comparison of spectra from samples exposed under the same conditions.

In order to identify the trapping sites generated by the plasma exposure in the investigated samples under the given exposure conditions we used the comparison of the TDS spectra of annealed and unannealed samples without history (figure 4). It is evident that the history of prior exposures has the same effect on the shape of the TDS spectrum and total retention as does the absence of annealing-it enhances the low-temperature release peak. This suggests that this lowtemperature peak is associated with a specific kind of trap, the concentration of which decreases upon annealing and increases by plasma exposure. It is known that annealing decreases the amount of thermodynamically non-equilibrium defects, such as dislocations, and non-equilibrium concentration of vacancies. This might be an explanation for the decrease in 
the low-temperature peak by annealing. On the other hand, vacancies can be generated by the high-flux plasma exposure as a result of plastic deformation due to high mechanical stresses created by the deuterium concentration strongly exceeding the solubility limit $[12,15,16]$. Dislocations themselves are probably too weak traps to retain deuterium at room temperature, as was discussed above. This suggests that the low-temperature release peak on the TDS spectra of the investigated samples corresponds to the trapping on vacancies. This agrees with our previous results [4], as well as with the results published in [17], where it has been discussed that in unpolished tungsten damaged by $\mathrm{MeV}$ range $\mathrm{W}$ ions the low-temperature $\mathrm{D}_{2}$ desorption peak might contain contributions from the release of deuterium trapped on vacancies. Consequently, this implies that the high-flux lowenergy plasma exposure of tungsten and tungsten alloys results in a modification of these materials, which manifests itself as an increase in the density of vacancies, which are subsequently responsible for the enhanced trapping-i.e. the history effect.

\section{Conclusions}

The deuterium retention in W-Ta alloys, exposed to high-flux plasmas, was experimentally studied. For the first time, the retention in these alloys was compared with that in pure $\mathrm{W}-$ an issue necessary to clarify in order to evaluate the possible use of W-Ta instead of tungsten as a material for plasma-facing components. The main conclusion is that for the conditions used in the experiments-ion flux $\sim 10^{24} \mathrm{~m}^{-2} \mathrm{~s}^{-1}$, ion fluence $\sim 5 \times 10^{25} \mathrm{~m}^{-2}$, ion energy $\sim 50 \mathrm{eV}$, surface temperature $\sim 480 \mathrm{~K}$-neither $\mathrm{W}$ nor any of the investigated $\mathrm{W}-\mathrm{Ta}$ grades exhibit systematically higher retention as compared with the others.

The desorption spectra of both investigated W-Ta grades consist of one major release peak at $\sim 500 \mathrm{~K}$ with desorption tails stretching into the high-temperature region. Desorption spectra of the investigated $\mathrm{W}$ targets also have a release peak at $\sim 500 \mathrm{~K}$; in some cases they have in addition an unresolved high-temperature peak at $600-650 \mathrm{~K}$. The absence of additional release peaks on the desorption spectra of W-Ta samples as compared with those of $\mathrm{W}$ indicates that alloying with Ta does not introduce additional kinds of traps. The proximity of the values of the total retained amount for all investigated grades shows that the presence of Ta does not significantly influence the concentration of trapping sites either.
A clear influence of the exposure of a target to plasma has been observed on the deuterium retention for a subsequent exposure, i.e. the history effect. It was observed that the history effect leads to an increase in deuterium retention by up to $130 \%$. This indicates that significant generation of trapping sites for deuterium occurs as a result of low-energy, high-flux plasma exposure.

\section{Acknowledgments}

This work, supported by the European Communities under the contract of Associations between EURATOM and SCK.CEN, was carried out within the framework of the European Fusion Development Agreement. The views and opinions expressed herein do not necessarily reflect those of the European Commission.

\section{References}

[1] Clark R. and Reiter D. 2005 Nuclear Fusion Research (Berlin: Springer)

[2] Hino T. 1998 Fusion Eng. Des. 39-40 227-33

[3] Zayachuk Y., Bousselin G., Schuurmans J., Gasparyan Yu., Uytdenhouwen I. and Van Oost G. 2011 Fusion Eng. Des 86 1153-6

[4] Zayachuk Y., 't Hoen M.H.J., Uytdenhouwen I. and Van Oost G. 2011 Phys. Scr. T145 014041

[5] van Rooij G.J. et al 2007 Appl. Phys. Lett. 90121501

[6] Quastel A.D., Davis J.W., Haasz A.A. and Macaulay-Newcombe R.G. 2006 J. Nucl. Mater. 359 8-16

[7] Eleveld H. and van Veen A. 1994 J. Nucl. Mater. 212-215 1421-5

[8] Debelle A., Barthe M.F. and Sauvage T. 2008 J. Nucl. Mater. $376216-21$

[9] Moshkunov K.A., Schmid K., Mayer M., Kurnaev V.A. and Gasparyan Yu.M. 2010 J. Nucl. Mater. 404 174-7

[10] Yamagiwa M., Nakamura Y., Matsunami N., Ohno N., Kajita S., Takagi M., Tokitani M., Masuzaki S., Sagara A. and Nishimura K. 2011 Phys. Scr. T145 014032

[11] Ogorodnikova O., Roth J. and Mayer M. 2003 J. Nucl. Mater. 313-316 469-77

[12] Alimov V., Roth J. and Mayer M. 2005 J. Nucl. Mater. 337-339 619-23

[13] Ogorodnikova O., Roth J. and Mayer M. 2008 J. Nucl. Mater. $373254-8$

[14] Haasz A., Davis J., Poon M. and Macaulay-Newcombe R. 1998 J. Nucl. Mater. 258-263 889-95

[15] Condon J.B. and Schober T. 1993 J. Nucl. Mater. 2071

[16] Lindig et al 2011 Phys. Scr. T145 014039

[17] 't Hoen M.H.J., Tyburska-Pueschel B., Ertl K., Mayer M., Rapp J., Kleyn A.W. and Zeijlmans van Emmichoven P.A. 2012 Nucl. Fusion 52023008 